\title{
The Role of Visual Effects: An E-Commerce Perspective on the Nigerian Arts and Crafts
}

\author{
${ }^{1}$ Afeez Babatunde Siyanbola, $\mathbf{P h D}$ \\ ${ }^{2}$ Michael Abiodun Oyinloye, PhD \\ ${ }^{3}$ Johnson O. Oladesu, PhD \\ ${ }^{4}$ Adedola Olayinka Adeyemi, PhD \\ 1,2,3,4 Department of Fine and Applied Arts \\ Olabisi Onabanjo University, Ago-Iwoye, Nigeria
}

Corresponding Author: Afeez Babatunde Siyanbola, Email: afeezsegun@yahoo.com Copyright 2021 (C) Author/s and the Publisher

\begin{abstract}
This paper explores the role of colour and visual weight in developing craftsential ecommerce platform for enhancing the patronage of Nigerian arts and crafts. The paper articulates the impressive embrace of e-commerce as a viable alternative to physical retail shopping. The graphic user interface of craftsential e-commerce platform developed to exclusively promote arts and crafts was explored vis-à-vis colours and visual weight of the sites visual indicators and icons. The study administered the questionnaires on three hundred and thirteen respondents constituting of e-commerce users, graphic designers/artists and programmers. Statistical Package of Social Science (SPSS) was used to analyze the results. Findings revealed that the colourful graphic user interface (look and feel) of e-commerce stores facilitates immersive shopping experience online and concise visual weight and direction in the atmospheric cue of e-commerce stores, enhancing navigation. The study recommended that makers and sellers of Nigerian crafts should explore the limitless opportunities offered by e-commerce to leverage an impressive market embrace of their products that transcend their geographical constrains. In addition, to stimulate shopper's interest, the images of retailed craft works displayed on e-commerce stores should reflect the product merchandizing, clarity and attractiveness that enhance shopping experience.

Keywords: Visual weight, visual direction, craftsential, Graphic User Interface (GUI)

\section{Introduction}

Human beings are naturally endowed with the potentials of influencing phenomenal developments and transformations in their immediate environment. Art and craft works are fundamental in the socio-economic advancement of developing and developed societies. Seemingly, culture in Nigeria is the most positively multi-ethnic, and it gives a lot of value to different types of arts, which primarily include ivory
\end{abstract}


The Role of Visual Effects: An E-Commerce Perspective 2

carving, grass weaving, wood carving, leather works and calabash decorations, pottery, painting, glass, metal works, and cloth weaving (Saheed 11).

Art remains a symbolic representation of the Nigerian socio-cultural inclinations. Crafts development in Nigeria takes on the peculiarities of the diverse cultures and traditions that make up Nigeria (Onyegbu). Functionality and utilitarian significance of art consistently enhanced the development of creative local industries whose products are continually embraced despite the barrage of foreign made products in the Nigerian market. Cultural products are not readily available for patronage by consumers in the Nigerian market whereas their foreign contemporaries can easily be gotten with ease. The graphic designer collaborates with computer programmers who create the sites database and ensure functionality of the site page. David Farkas and Jean Farkas further highlighted the role of a graphics design in web development as:

1) Adding aesthetic appeal to website interface

2) Helping to express the theme of the website

3) Helping to show the logical relationships among all elements that appear on the page, both core content elements and elements of the interface. (2)

Graphic design elements include the use and size of images, the use of animation, the number of words per line and size of characters, symbols, and the display of colour (Kang and Corbitt 4; Rosen and Purinton 790).

Apparently, the spontaneity of online shopping has remarkably influenced an unprecedented acceptance of online retailership across the globe in recent times. The consumer is just a click away from product purchase and its delivery at his or her doorstep (Khan 19). The online retailership is broadly known as electronic commerce. E-commerce is a business transaction that involves the buying and selling of products, services, and information via computer networks including the Internet (Liang et al. 310; Timmers 200, Shrivastava 45).

However, an evaluation of the potentials and challenges of promoting Nigerian indigenous crafts on e-commerce retail stores with a view of enhancing online retailership and promote the richness of Nigerian indigenous crafts will further reposition e-retailership to stimulate growth of local economies.

\section{Aim}

This study explores the role of colour and visual weight in the design and development of craftsential graphic user interface for promoting Nigerian arts and crafts. The specific objectives of this research are:

1) To evaluate the graphic user interface of craftsential e-commerce platform

2) To assess the relevance of craftsential e-commerce platform in promoting Nigerian arts and crafts.

\section{Review of Literature \\ Colour and Aesthetics}

Human responses to the colour usage are typically dependent on the personal penchant, experiences, childhood background, cultural differences and others. Colours are emotive and persuasive in influencing actions and feelings. However, in a study titled "Impact of Color on Marketing," the researchers found that up to 90\% of snap judgments made about products can be based on the colour alone, depending on the product (Ciotti). 
The Role of Visual Effects: An E-Commerce Perspective 3

Colours are critical in branding; the results from another study show that the relationship between brands and color hinges on the perceived appropriateness of the color being used for the particular brand (Ciotti). The color has been identified as a pivotal component of e-commerce websites (Lemoine).

Aesthetic experience of any given color is strongly influenced by its participation in combinations of two or more colors (Schloss and Palmer). When discussing color aesthetics, it is therefore necessary to consider not only how much people like individual colors (Hurlbert and Ling 17; Schloss and Palmer 553), but how colors interact with forms and contents. Aesthetic in form and color is fundamentally significant in art and design. (Kang, Qin and Zhang 3) in their paper titled "computeraided color aesthetic evaluation method based on the combination of form and color". (Kang, Qin and Zhang 3) summarized that the factors of color aesthetic measure such as the color area, distance, and connection style of color blocks by a psychophysical field experiment and established a harmonic intensity model. The model not only has an important significance to reveal the harmony mechanism of the form-color field, but also has important academic values for artificial intelligence, cognitive science, perception science, and the development of psychology.

\section{Color Psychology}

The psychology of color is based on the mental and emotional effects colors that have on people in all facets of life ("Colour Psychology"). The colour psychology is subjected to mental biasness based on individual interpretation and perceptions. However, researches have proven reliably that colours have some certain psychological properties (Elliot 360; Kurt and Osueke; Hill and Barton 293). They relate respectively to the body, the mind, the emotions and the essential balance between these factors (“Colour Effects”).

\section{Visual weight}

The visual weight is the intensity of force that an element exerts in a design. The elements that enormously attract the eyes in a composition have a greater visual weight than other elements. The visual elements like shape, size, typography, colour, space and texture largely determine the area of the design composition that exerts much force. The visual is an important concept in creating hierarchy, flow, rhythm and balancing in website design (Bradley).

The dexterity exemplify in the application of visual elements specifically determines the success of virtual stores. The homepage of online store is arranged to enable listed products, labels, and clickable buttons that have mouseover features that attract the eyes. It is also necessary for the images of listed products to have a subtle background shadow for it to possess a depth of field, which enhances visual stability and increases its visual weight.

\section{Visual Direction}

The visual direction directs the eyes to a particular area. It indicates the direction of visual forces and movements in design. Whereas the visual weight is shouting "Look at me!”, the visual direction is saying "Look over there!” (Bradley). The visual directions are perceptive lines that point or connect the visual elements. 
The Role of Visual Effects: An E-Commerce Perspective 4

In the physical stores, there are directional signages that guides and directs the buyer's movement in a shopping mall. It is also important for the online stores to create the atmospheric visual cues that enhance navigation on the e-commerce site. The visual direction cues online include arrows, pointing fingers, element shapes and location.

\section{Research Design}

The quantitative research methodology was adopted for this study (Bryman 20) acknowledged that quantitative research approach places emphasis on numbers and figures in the collection and analysis on empirical data. Respondents were purposively sampled. The study administered the questionnaires on a total of 313 respondents comprising of 286 e-commerce users, 20 graphic designers and artists, 5 computer programmers and 2 e-commerce business executives. Amongst the sampled e-commerce users, there are 117 (40.9\%) males and 169 (59.1) females. 11 (55\%) males and 9 (45\%) females are the graphic designers and artists sampled. The programmers are $3(60 \%)$ males and 2 (40\%) females while the e-commerce business executives constitute of 1 male (50\%) and 1 (50\%) female.

Statistical analysis utilized five (5) point Likert scale formats Strongly Agree, Agree, Undecided, Disagree and Strongly Disagree to collect data from the population. The data collected was analyzed using mean. The nominal scores and records were attained using Likert scale model: Strongly Agree $=5$, Agree $=4$, Undecided $=3$, Disagree $=2$ and Strongly Disagree $=1$. These were calculated as $5+4+3+2+1=15 / 5=3$ (Likert Scale Criterion). The score of each item was summed and the arithmetic mean calculated for each item. The mean is compared with Likert Scale criterion above. If mean is equal to or above (greater than) the Likert criterion (3.0) then the item is accepted. But if the mean is lower than the Likert criterion (3.0) then the item is rejected

\section{Results}

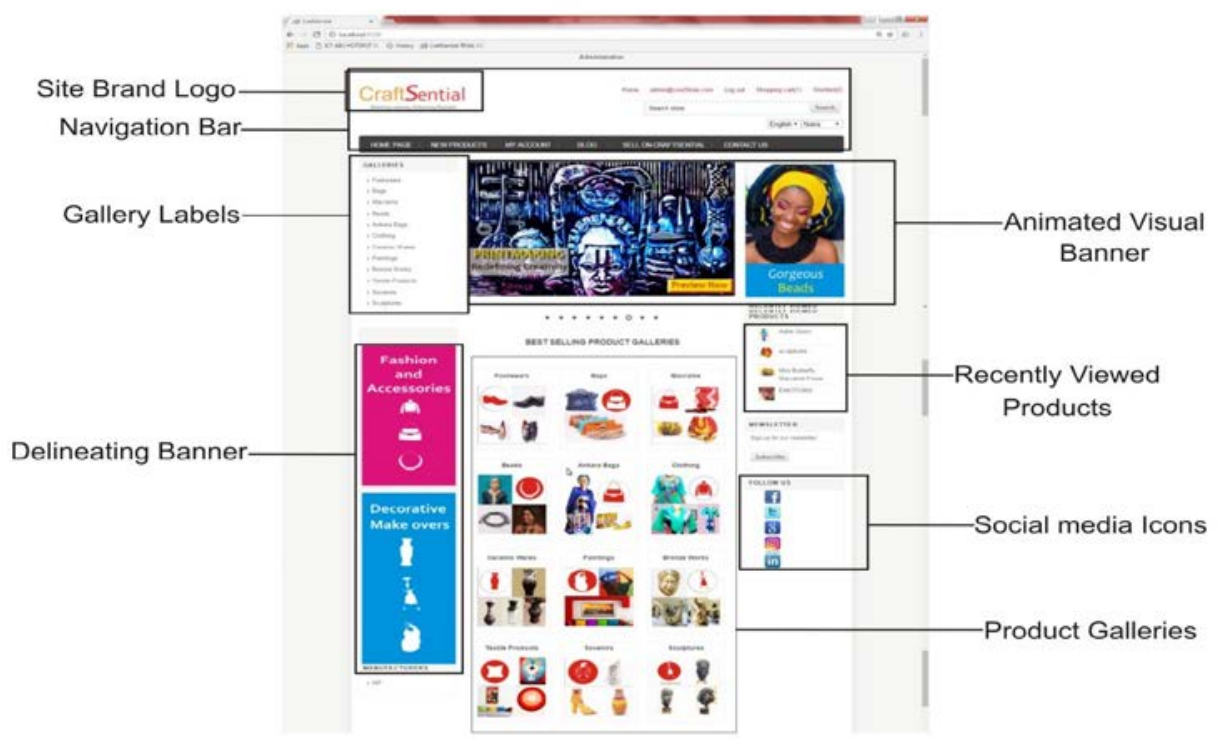

Fig. 1 Graphic User Interface of Craftsential E-commerce Platform (2018), Authors fieldwork. 
The Role of Visual Effects: An E-Commerce Perspective 5

Table 1:

Results of evaluation of Craftsential E-commerce Store

\begin{tabular}{|c|c|c|c|c|c|c|c|c|}
\hline SN & & SD & A & $\mathrm{U}$ & $\mathrm{D}$ & SD & $\mathrm{M}$ & Remark \\
\hline 1 & $\begin{array}{l}\text { I like the positioning of craftsential brand logo } \\
\text { (Refer to No.1) being on the top left hand } \\
\text { corner of the navigational bar }\end{array}$ & 120 & 90 & 3 & & & 4.3 & Accepted \\
\hline 2 & $\begin{array}{l}\text { The colours on the e-commerce site are } \\
\text { appropriate }\end{array}$ & 128 & 160 & 25 & & & 4.3 & Accepted \\
\hline 3 & The textual information provided are adequate & 107 & 151 & 35 & 20 & & 3.7 & Accepted \\
\hline 4 & $\begin{array}{l}\text { The e-commerce site is navigable (users can } \\
\text { look through and identify each segment) }\end{array}$ & 150 & 155 & 3 & 5 & & 4.4 & Accepted \\
\hline 5 & $\begin{array}{l}\text { The e-commerce site design is not congested } \\
\text { with uneccessary colours, shapes and texts }\end{array}$ & 64 & 99 & 56 & 23 & 71 & 3.1 & Accepted \\
\hline 6 & $\begin{array}{l}\text { I can identify the different product galleries on } \\
\text { the site clearly }\end{array}$ & 120 & 180 & 10 & & 13 & 4.3 & Accepted \\
\hline 7 & $\begin{array}{l}\text { The product galleries are visual gateways to the } \\
\text { category pages on craftsential (Refer to No. 5) }\end{array}$ & 144 & 169 & & & & 4.4 & Accepted \\
\hline 8 & $\begin{array}{l}\text { There is consistency in the design and } \\
\text { implementation of the sites user interface }\end{array}$ & 18 & 5 & & & & 4.7 & Accepted \\
\hline 9 & $\begin{array}{l}\text { Promotion of arts and craft for sale on an e- } \\
\text { commerce retail platform will enhance its patronage }\end{array}$ & & 12 & 15 & & & 5 & Accepted \\
\hline 10 & $\begin{array}{l}\text { The showcase of Nigerian art works on an e- } \\
\text { commerce platform communicates values and } \\
\text { potentials of the creative industry to the world }\end{array}$ & & 4 & 13 & 3 & 5 & $\begin{array}{l}3.7 \\
5\end{array}$ & Accepted \\
\hline
\end{tabular}

Source: Authors Fieldwork, 2018 (SA = Strongly Agreed, A = Agree, U = Undecided, D $=$ Disagree, $\mathrm{SD}=$ Strongly Disagree, $\mathrm{M}=$ Mean)

Table 2:

Graphical Representation of Table 1

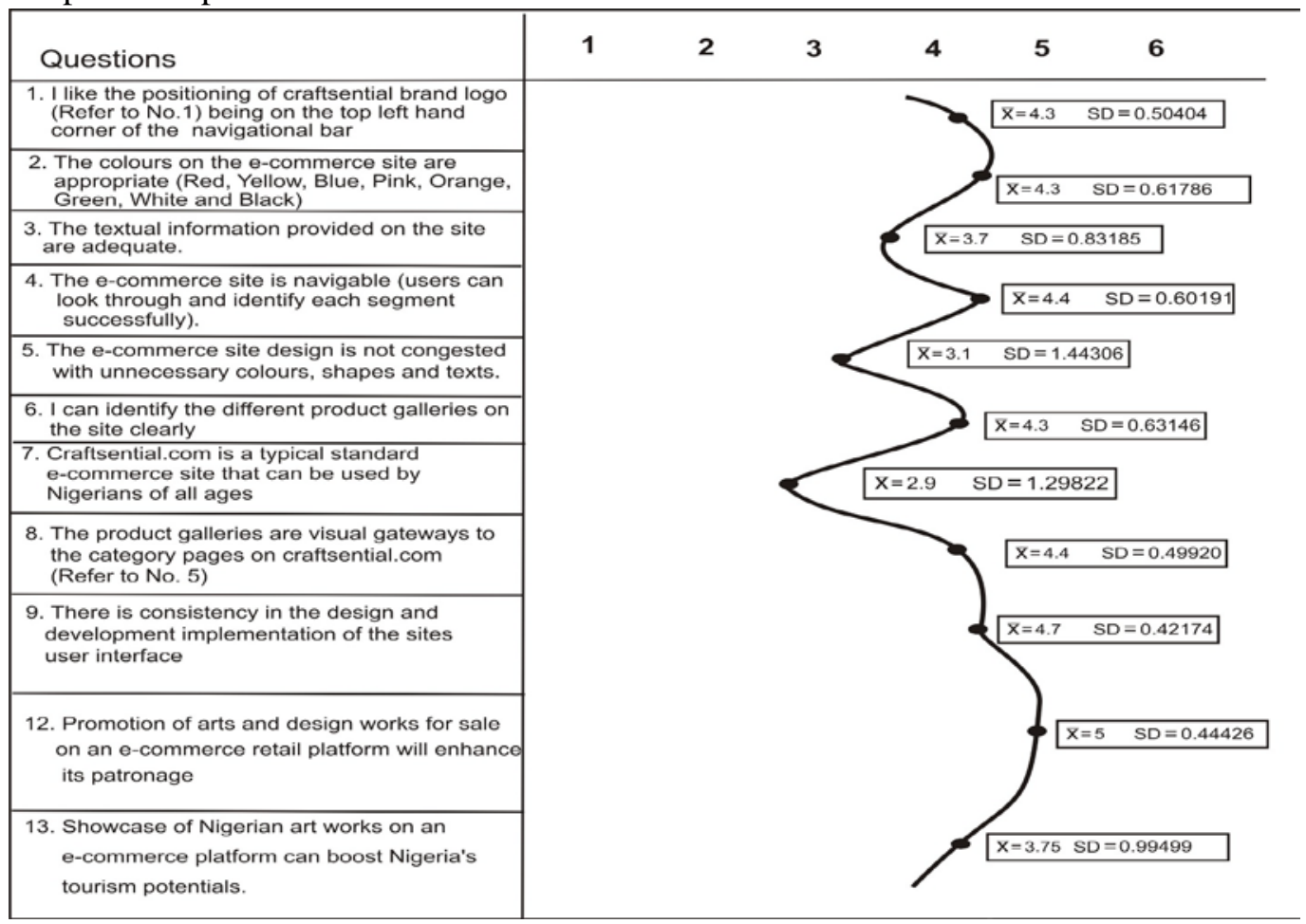

Source: Authors Fieldwork, 2018

SCHOLARS: Journal of Arts \& Humanities

Volume 3, No. 1, February 2021 
The Role of Visual Effects: An E-Commerce Perspective 6

\section{Discussion}

In table 4.26, the respondents assert that the appropriate positioning of craftsential e-commerce site brand logotype (Mean $=4.3$ ). The positioning of the logotype corresponds with the typical placement and situation of logotypes on websites. The use of colours such as red, yellow, blue, pink, orange, green, white and black are suitable for e-commerce site (Mean $=4.3$ ). Some of these colours are harmonious, complementary and contrasting as these colours are essential in highlighting specific products and product collections thereby facilitating spontaneous directional cues on an e-commerce site. The adequacy of textual information is emphasized by respondents (Mean $=3.4)$. The product information accentuates merchandizing on the site and connects shoppers to the e-commerce site. The different segments of craftsential ecommerce site are navigable (Mean $=4.4$ ). There is a consistent spatial arrangement in the positioning of the visual icons and indicators across the site pages.

According to Roggio, a good navigation improves online shopping experience and helps merchants increase sales and profits online. In addition, the consistency in the spatial positioning of the site visual elements is anchored on the intuitive visual weight and concise visual direction. The craftsential e-commerce site is not unnecessarily congested with colours, shapes and texts (Mean =3.1). Although the vibrant application of communicative visual elements on the e-commerce site signifies the genre of the site, it is a one-stop shop for Nigeria art and craft works, so the graphic user interface of craftsential e-commerce store showcases the richness of Nigeria-made artworks. The graphic user interface design is expressive, the colours are adequately utilized to enliven the "textural fabric" of the site pages to arouse pleasure and stimulate the shopper to make purchase on the site. This feature conforms to the Mehrabian and Runsell theory of stimuli and response. The Respondents could identify the different product galleries on the e-commerce store's homepage (Mean $=4.3$ ). The visibility and easy identification of elements on the e-commerce store enhance efficiency in shopping online. Ji, Park, Lee and Yun noted that a critical criterial of system evaluation is the ease of identification and learning of features that assist users to have high level of productivity when shopping online. The shoppers should be able to scan labels and instantly understand what those labels represent within the store context (Roggio).

The respondents disagreed that craftsential e-commerce store can be used by Nigerians of all ages (Mean $=2.9$ ). This result implies that the target users of the site are not all age groups but for the tech-savvy age group, which typically start from age fifteen upward. The high penetration of internet enabled devices such as smartphones makes the site a click away from the users. The product galleries are visual gateways to the category pages on craftsential (Mean $=4.4)$. The graphic designers and programmers amongst the respondents agreed that there is consistency in the design and implementation of the sites user interface (Mean = 5.2). Ji, Park, Lee and Yun criterial for the system evaluation posited that the websites user interface must be designed consistently. The promotion of arts and craft works for sale on an e-commerce retail platform enhances the patronage (Mean $=5$ ). This outcome answers the research question three. The graphic-designer and artist respondents agreed that the showcase of Nigerian art works on an e-commerce platform can boost Nigeria's tourism potentials. 
The Role of Visual Effects: An E-Commerce Perspective 7

\section{Findings}

1) The colourful graphic user interface (look and feel) of the e-commerce stores facilitates immersive shopping experience online.

2) The concise visual weight and direction in the atmospheric cue of e-commerce stores enhance navigation.

3) Alluring the graphic user interface in the e-commerce technological platform should give shoppers the sensory experiential shopping user's sensory experiences.

4) The promotion of arts and craftworks for sale on an e-commerce retail store advances patronage.

\section{Conclusion}

E-commerce has simplified the process of buying and selling globally. The benefits are enormous and far-reaching; businesses can now be transacted without limit or barriers. The areas not reached by the physical retail stores can now access to goods and services online from any part of globe. The unlikeliness of shopping for Nigerian indigenous crafts online can be addressed by creating an e-commerce platform exclusively deployed to promote the Nigerian crafts. Appealing the visuals and userfriendliness of e-commerce stores enhance the shopping experience. The site features coherently integrated with a dynamic approach to aesthetics, interactivity pleasant userexperience, responsiveness, ease of use and intuitive navigations enables an exciting shopping online.

\section{Recommendations}

The recommendations highlighted below were deduced from the outcome of this study:

1) It is necessary for the makers and sellers of Nigerian crafts to explore the limitless opportunities offered by e-commerce to leverage an impressive market embrace of their products that transcend their geographical constrains.

2) The makers of art and craft works must embrace best practices in their valuechain of production in churning out graceful works that will attract patronage online.

3) To stimulate the shopper's interest, the images of retailed craft works displayed on e-the commerce stores should reflect the product merchandizing, clarity and attractiveness that enhance shopping experience.

4) The choice of colours on the website should be determined by the theme of the site.

\section{Works Cited}

“Color Psychology: The Emotional Effects of Colors.” Art Therapy, 12 March 2018, www.arttherapyblog.com.

“Colour Effects.” Psychological Properties of Colours, 29 February 2018, www.colouraffect.co.uk. 
Bradley, Steven. "Design Principles: Visual Weight and Direction.” Smashing Magazine, 15 October 2015, www.smashingmagazine.com.

Bryman, A. Social Research Methods. O University P, 2001.

Ciotti, Gregory. "The Psychology of Color in Marketing and Branding.” Helspscout, 12 June 2017, www.helpscout.net.

Elliot, Andrew "Color and Psychological Functioning: A Review of Theoretical and Empirical Work.” Frontiers in Psychology, 2015, vol 6, p. 368.

Farkas, David and Jean Farkas. Principle of Graphics Design, Longman, 2002.

Hill, Russell A. and Robert A. Barton. "Psychology: Red Enhances Human Performance in Contests.” Nature, vol. 435, June 2005, pp. 293-435.

Hurlbert, Anya C. and Yazhu Ling. "Biological Components of Sex Differences in Color Preference.” Current Biology, vol. 17, no. 16, August 2007, pp. 623-625.

Ji, Yong Gu, Jun Ho Park, Cheol Lee, and Myung Hwan Yun. "A Usability Checklist for the Usability Evaluation of Mobile Phone User Interface.” International Journal of Human-Computer Interaction, vol 20, no3, 2006, pp. 207-231.

Kang, Kyeong and Brian J. Corbitt. "Effectiveness of Graphical Components in Web Site E-commerce Application-A Cultural Perspective.” The Electronic Journal of Information Systems in Developing Countries, vol 7, no. 2, 2001, pp. 1-6.

Kang, Wenke, Qin sheng-feng and Quan Zhang. “Computer-Aided Color Aesthetic Evaluation Method Based on the Combination of Form and Color."

Mathematical Problems in Engineering, vol. 1, 2015, pp. 1-8.

Khan, Abdul Gaffar. "Electonic Commerce: A Study on Benefits and Challenges in an Emerging Economy.” Global Journal of Management and Business, vol. 16, no.1, 2016, pp. 18-22.

Kurt, Sevinc and Kelechi Kingsley Osueke. "The Effects of Color on the Moods of College Students.” SAGE Open, 28 February 2014, https://journals.sagepub.com/doi/full/10.1177/2158244014525423.

Lemoine, Jean-Francois. "L'influence de l'atmosphère des sites web marchands sur les réponses desinternautes." 15 et 16 24ème congrès international de l'association française du marketing, Paris, mai 2008, CDRom.

Liang, Ting-Peng, Efraim Turban, Jae Kyu Lee, David King and Deborrah Turban. Electronic Commerce: A Managerial Perspective. Prentice Hall, 2000.

Manlapas, Claire. "Graphic Design ABCs: A Glossary of Basic Design Terms.” Uncreative, 4 December 2014, https://www.ucreative.com/resources/designterms/.

Onyegbu, V.M. “As Nigeria celebrates World Crafts Day.” Edited by Kala Moshood, 2011, www.gbooza.com.

Roggio, Armando. "7 Ways to Improve Ecommerce Site Navigation." PracticalEcommerce, 15 June 2015, www.ecommercepractical.com.

Rosen, D.E. and E. Purinton "Website Design: Viewing the Web as a Cognitive Landscape.” Journal of Business Research, vol. 57, no. 7, 2004, pp. 787-794.

Saheed, Zakaree S. "Adire Textile: A Cultural Heritage and Entrepreneurial Craft in Egbaland, Nigeria.” International Journal of Small Business and Entrepreneurship Research, vol. 1, no. 1, March 2013, pp. 11-18. 
Schloss, Karen B. and Stephen E. Palmer. "Aesthetic Response to Color Combinations: Preference, Harmony, and Similarity.” Attention Perception Psychophys, vol. 73, no. 2, 2011, pp. 551-571.

Shrivastava, K. "An Approach of Shopping in 21st Century: Online Shopping.” The SIJ Transactions on Computer Science Engineering \& Its Applications (CSEA), vol. 1, no. 4, 2013.

Timmers, Paul. Electronic Commerce - Strategies and Models for Business-to-Business Trading. John Wiley \& Sons, 2000. 